Published as: A.D.S. Gillies and H.W. Wu, Dust Measurement and Control, Proceedings, Queensland Mining Industry Health and Safety Conference, Townsville, 323325 August 2001. 


\title{
Dust Measurement and Control in Thick Seam Mining
}

\author{
by \\ A D Stewart Gillies ${ }^{1}$ and $\mathrm{Hsin}$ Wei $\mathrm{Wu}^{2}$
}

\begin{abstract}
Australia is mining at greater seam thicknesses than most similar western countries and particularly the US. The approaches developed by other countries and previous research and innovation are not necessarily directly transferable. Furthermore, the increasing scale of production in thick seam longwalls challenges the maintenance of safe and healthy face environments in Australian collieries. High production rates, longer faces and higher ventilation quantities and velocities further exacerbate dustiness.
\end{abstract}

An ACARP funded scoping study has been undertaken to examine dust problems that are being faced by Australian thick seam longwall mine operators, evaluate options and recommend priorities for improvement. The study involved a number of stages. A detailed survey of six Australian thick seam mine operators to identify individual mine issues was undertaken. A comprehensive literature review, with emphasis on publications from the last ten years was undertaken on Australian and foreign developments. Views and advice from recognised dust experts both within Australia and overseas were sought. Some approaches to assessment of dust compliance and analysis of trends exhibited were undertaken. Both analysis and evaluation were undertaken on some options for improvement.

This paper describes details of the questionnaire survey of six Australian thick seam miners operators to identify individual mine issues related to dust measurements and controls. It also presents some potential thick seam longwall dust issues based on the analysis of dust survey results from both published US data and from Joint Coal Board data.

\section{INTRODUCTION}

The increasing scale of underground longwall mining operations challenges the maintenance of safe and healthy face environments in Australian collieries. This is particularly a challenge in controlling respirable dust in thick seam mining using longwall extraction.

Thick seam mining and particularly longwall production is relatively new to Australia and the number of mines involved is increasing. Thick seams are those currently of about 3.5 to $5.0 \mathrm{~m}$ (and possibly of greater thickness in the future) being extracted in one pass. Thick seam extraction presents additional problems in dust measurement and control above those faced by medium extraction heights of 1.8 to $3.5 \mathrm{~m}$. These include major face slabbing of coal, the leaving of substantial coal in the roof, high average production rates and peak tonnages and high air velocities required to dilute seam gases and because face length are increased. Australia is mining at greater seam thicknesses than most similar western countries, and particularly the US. The approaches developed by other countries and previous research and innovation are not necessarily adequate for Australian challenges or directly transferable.

The intention of the study was to develop a blue print for future dust remediation in thick seam mining. In the first instance, this project proposed a scoping study wherein the problems being faced by Australian producers were identified. The project was restricted to the technical issues of measurement and control of respirable dust within the underground mine environment The study undertook a detailed survey of Australian thick seam miner operators to identify individual mine issues. Extensive literature reviews were undertaken and advice sought from recognised dust experts both within Australia and overseas. An examination of some approaches to assessment of dust compliance and analysis of trends exhibited was undertaken. Analysis and evaluation of options for improvement concluded the study.

This paper describes details of the questionnaire survey of six Australian thick seam miners operators to identify individual mine issues related to dust measurements and controls. It also examines some

\footnotetext{
${ }^{1}$ Reader in Mining Engineering, University of Queensland, Brisbane, 4072, AUSTRALIA

${ }^{2}$ Research Fellow in Mining Engineering, University of Queensland, Brisbane, 4072, AUSTRALIA
} 
thick seam longwall dust issues based on the analysis of dust survey results from both published US and Australian Joint Coal Board (JCB) data.

\section{QUESTIONNAIRE SURVEY OF THICK SEAM LONGWALL OPERATORS}

In order to achieve a better understanding of respirable dust issues faced by the Australian thick seam longwall operators, a questionnaire survey on respirable dust in thick seam coal mines was undertaken. A total of six mines were surveyed through interviews with mine personnel and associated underground visits (Gillies, 2001).

\section{Questionnaire Survey}

A questionnaire was used to interview mine personnel from selected Australian coal mines with a panel extraction height of more than $3.8 \mathrm{~m}$. In brief the following information was sought.

1. Mine operation and production details including extraction methods used, annual production, extraction depth, working seam thickness, development and panel extraction heights.

2. Ventilation network details such as underground ventilation monitoring systems, types and numbers of sensors installed, seam gas type and quantity, gas drainage system, gas concentration in ventilation air and the possibility of spontaneous combustion.

3. Specific questions on whether gas drainage will dry the coal, water infusion benefits, panel bleeders and their arrangements and ventilation simulation software in use.

4. Information on how the mines rank various issues such as respirable dust issues, geology/geotechnical considerations, methane gas, equipment availability or other in restricting longwall production expansion in Australian mines. Where does respirable dust rank, reason for considering respirable dust as a serious problem now or in the near future, and current approach to longwall shearer cutting sequences such as Unidi or Bidi?

5. Views on major dust challenge difference between thin seam and thick seam longwall mining.

6. Information on major sources of dust on the longwall face and in a development heading, system/arrangement of sprays used on face and longwall cutting sequence used for dust control.

7. Specified questions on the details of shearer clearer or other directional sprays used, whether shearer clearer or other spray configuration fully covering the face, any warrant on designs or operational changes to the shearer clearer, pressure applied at sprays and the effect on dust suppression if pressure increased.

8. Information on use of chemical surfactants, spalling of high faces creating a major dust source, dust issue from goaf caving, longwall face air quantity planned and measured, would more air on face assist dust reduction, how could more air quantity from whole mine ventilation network be delivered to face, maximum face air velocity beyond which airborne dust levels will be exacerbated, pattern or distribution of air along face, air escape through the goaf behind the chocks and personal face respirators used.

9. Additional information in the final section on issues such as Dust Control Plan formulated for longwall and development, whether a Dust Control Plan is part of the Mine Ventilation Plan, positioning of operators, details of face dust surveys and whether company (non-confidential) or other published data available on survey results.

\section{Survey Results Summary and Analysis}

A total of six mines were visited and surveyed, three from each of NSW and Queensland. Most of the mines were established in their present form in the 1990s. Five mines have an annual production rate of more than $3 \mathrm{mtpa}$ with two of these exceeding $5 \mathrm{mtpa}$. Seam thickness averaged $8.3 \mathrm{~m}$ with a range varying from 4.0 to $24.0 \mathrm{~m}$. Average Mains and Panel development height is $3.4 \mathrm{~m}$ with a range varying from 3.1 to $4.0 \mathrm{~m}$. Panel height averaged $4.3 \mathrm{~m}$ with a range varying from 3.8 to $5.0 \mathrm{~m}$.

\section{Gas and Ventilation Information}

All mines except one surveyed have both tube bundle and telemetry system for underground ventilation monitoring. All have installed various types of gas sensors and two have both air velocity and pressure sensors installed. Three mines have very low seam gas present $\left(<2 \mathrm{~m}^{3} /\right.$ tonne $)$, two are low (3-5 $\mathrm{m}^{3} /$ tonne), one moderate $\left(5-10 \mathrm{~m}^{3} /\right.$ tonne) and none are high ( $>10 \mathrm{~m}^{3} /$ tonne). Of the two mines with gas drainage systems in place, one used water infusion whenever and wherever possible 
and the other is considering this. All mines have potential for spontaneous combustion. Two mines used panel bleeders or ventilated behind the goaf. All mines surveyed used Ventsim ventilation network simulation software and one also used VNETPC.

\section{Ranking of Respirable Dust Issue}

A question was put on the priority of dust as a challenge. In general, equipment availability is considered as the most important issue by Australian thick seam coal mine operators in restricting longwall production expansion. This is followed by geological and geotechnical considerations and methane gas problems. Table 1 shows a summary of comments on the most important issue in restricting longwall production expansion from mines surveyed.

Table 1 Comments on important issue in restricting longwall production expansion

\begin{tabular}{|c|c|c|c|c|c|}
\hline \multirow{2}{*}{ Mine } & \multicolumn{6}{|c|}{ Comments (ranking 1: most important and 4 least important) } \\
\cline { 2 - 6 } & Dust & Geotechnical & CH $_{\mathbf{4}}$ Gas & Equipment & Others \\
\hline \hline A & 4 & 3 & 2 & 1 & \\
\hline B & 4 & 2 & 3 & 2 & 1 \\
\hline C & 3 & 2 & 4 & 1 & \\
\hline D & 4 & 1 & 3 & 1 & \\
\hline E & 2 & 1 & 3 & 4 & 2 \\
\hline F & 3 & & 4 & 1 & \\
\hline
\end{tabular}

For mines without serious methane gas issues respirable dust ranked as the third important issue affecting longwall production after equipment and geotechnical issues. Respirable dust is generally not an issue that will stop longwall production. In some case where silica levels were out of compliance the longwall production was slowed. However it was considered that the dust issues could usually be rectified by modifying mining procedures or by the use of personal protective equipment (PPE) to reduce dust exposure. Five out of the six mines surveyed considered respirable dust as a serious problem now or in the near future. Their reasons are mainly related to the health risk and visibility problem associated with respirable dust. However, most of the mines believed that use of PPE, shearer sprays, shearer and chock automation can rectify the problems associated with respirable dust.

All mines used Unidi longwall shearer cutting methods mainly due to production loading, clean up, ventilation and dust issues associated with Bidi. One had recently changed from Bidi due to dust. When asked what is the major dust challenge difference between thin seam and thick seam longwall mining most of the mines indicated that high production associated with thick seam longwall means more dust generation and increased face air quantity requirements.

Most of the mines considered shearer and chock advance are the major sources of dust on the longwall face (as shown in Table 2). This is followed by dust from the stage loader and the belt heading. Most of mines considered continuous miners are the major sources of dust in a development heading (as shown in Table 3). This is followed by shuttle car and belt heading. Half of the mines' surveyed considered spalling of high faces creates a major dust source. One mine indicated that a study into the relationship between slabbing and face abutment loading would be worthwhile. It is believed that slabbing would be reduced if chocks were advanced closer to the face.

Table 2 Major sources of dust estimated on the longwall face

\begin{tabular}{|c||c|c|c|c|c|}
\hline Mine & Shearer \% & $\begin{array}{c}\text { Chock Advance } \\
\%\end{array}$ & $\begin{array}{c}\text { Stage Loader } \\
\%\end{array}$ & $\begin{array}{c}\text { Belt Heading } \\
\%\end{array}$ & $\begin{array}{c}\text { Others } \\
\%\end{array}$ \\
\hline \hline & 50 & 50 & & & \\
\hline A & 50 & 25 & 10 & 5 & 10 \\
\hline B & 25 & 35 & 20 & 20 & \\
\hline C & Largest & Worst & Well contained & $\begin{array}{c}\text { Not } \\
\text { considered }\end{array}$ & \\
\hline D & 45 & 45 & $5-10$ & $<5$ & \\
\hline E & 30 & 20 & 20 & 5 & 20 \\
\hline F & & & & & \\
\hline
\end{tabular}


Table 3 Major sources of dust estimated in a development heading

\begin{tabular}{|c||c|c|c|c|}
\hline Mine & $\begin{array}{c}\text { Miner } \\
\%\end{array}$ & $\begin{array}{c}\text { Shuttle Car } \\
\%\end{array}$ & $\begin{array}{c}\text { Belt Heading } \\
\%\end{array}$ & $\begin{array}{c}\text { Others } \\
\%\end{array}$ \\
\hline \hline & 90 & 10 & & \\
\hline A & 90 & 5 & & 5 \\
\hline B & 80 & 10 & 10 & \\
\hline C & ${\mathrm{High} \mathrm{SiO}_{2}}$ & Minor & Minor & \\
\hline D & & & & \\
\hline E & 100 & & & \\
\hline F & & & & \\
\hline
\end{tabular}

All mines surveyed used shearer mounted sprays on the face. Sprays are also installed at the stage loader. Most of mines have sprays on chocks but are not in use. Most of mines used a modified Unidi cutting method cutting mainly from TG to MG with snake at the TG. Only three mines have used shearer clearer sprays. Of these, two indicated that the shearer clearer configuration used is not fully covering the face. All three mines indicated that designs or operational changes to shearer clearer were warranted to achieve a better coverage. Four mines provided data on mine pressure at sprays. Pressures indicated by these mines have a wide range from $0.7 \mathrm{MPa}$ to $8 \mathrm{MPa}$ ( $80 \mathrm{bar}$ ).

Three mines have investigated the use of chemical surfactants. Two of them indicated that chemical surfactants are not considered to be cost-effective.

\section{Face Ventilation Arrangement}

Longwall face air quantity is generally targeted between 35 and $70 \mathrm{~m}^{3} / \mathrm{s}$ and averaged around $50 \mathrm{~m}^{3} / \mathrm{s}$. Most of the mines indicated that the targeted amount of air was normally achieved. A divided view on whether more air on the face would assist dust reduction was observed. Three mines believed that more air at face would not assist dust reduction but increase dust pick up and disturb spray operation.

When asked whether more air quantity from the whole mine ventilation network could be delivered to the face most of the mines indicated that this is achievable with their current mine ventilation system by increasing the fan operating speed or number of fans in use.

Most of mines agreed that there is a maximum face air velocity (around $4 \mathrm{~m} / \mathrm{s}$ ) beyond which they thought airborne dust levels would be exacerbated. Four mines indicated that they have some knowledge of the pattern or distribution of air along the face length. Two mines indicated no air escapes through the goaf behind the chocks, three said some air escaped and the other indicated about 15 to $20 \mathrm{~m}^{3} / \mathrm{s}$ escaped through the goaf. All mines surveyed indicated that Airstream helmets and various face dust masks and filters are available for use by all personnel in the longwall panel.

\section{Dust Control Plan}

Most of mines have formulated a Dust Control Plan for their longwall but only one mine has also formulated a Dust Control Plan for development headings. Most of the mines (5 out of 6 ) indicated that a Dust Control Plan is not part of their Mine Ventilation Plan.

Three mines indicated that they are in the process of minimising the numbers of operators on the face. Four mines pointed out that the shearer can be remote controlled by an operator from a distance ranging from $5 \mathrm{~m}$ to $40 \mathrm{~m}$. Four mines indicated that chock operators were rotated during shift to minimise individual exposure but with some operational issues. Half of the mines undertake snaking at the Tailgate to limit the dust exposure to operators.

All mines undertook surveys of face dust levels on personnel but only half of the mines conducted surveys for area levels. All NSW mines have the Joint Coal Board (JCB) undertake the surveys. All Queensland mines have the Safety In Mines Testing and Research Station (SIMTARS) undertake their surveys. One Queensland mine also has had the JCB conduct surveys. Two thirds of the mines have the survey undertaken every three to six months as required by statutory regulations. The other two have the survey carried out three weekly or monthly. 


\section{THICK SEAM LONGWALL DUST ISSUES}

\section{US Longwall Dust Situation}

Thick seam longwall mining has become the most productive method of underground coal mining in Australia and record levels of production have been achieved in recent years. These ever improving production levels have potential to generate significantly higher quantities of respirable dust. In the mid 1990s, the Pittsburgh Research Center (PRC) initiated a surveillance effort to quantify the levels of dust being generated by various sources found on US longwalls, identify the types of dust control technologies in use and try to quantify the degrees of application for these control technologies (Colinet et al, 1996).

PRC conducted dust surveys at 13 longwall operating throughout the US. It collected information on existing operating practices on these longwall, identified the types of dust controls in use, documented the levels at which these controls are being applied and measured the respirable dust levels generated by the major sources on the longwall section to evaluate the relative effectiveness of the control technologies. During this study in order to identify the importance of seam thickness on generation of respirable dust on longwall section, information collected by PRC in the mid 1990s was re-analysed based on the seam thickness. The following table lists the dust contributions during mining from major longwall dust sources such as intake, stage loader/crusher, chock shield advance and shearer for each mine as calculated by Colinet et al (1996). Mines are listed in decreasing seam extraction height.

Table 4 Contributions during mining from major longwall dust sources

\begin{tabular}{|c|c|c|c|c|c|c|c|}
\hline \multirow[t]{2}{*}{ Mine } & \multirow{2}{*}{$\begin{array}{l}\text { Cutting } \\
\text { Height } \\
\text { (m) }\end{array}$} & \multirow{2}{*}{$\begin{array}{c}\text { Cutting } \\
\text { Rate } \\
\text { (t/min) }\end{array}$} & \multirow{2}{*}{$\begin{array}{c}\text { Face Air } \\
\text { Quantity } \\
\left(\mathrm{m}^{3} / \mathrm{s}\right)\end{array}$} & \multicolumn{4}{|c|}{ Contributions from Major Dust Sources } \\
\hline & & & & $\begin{array}{c}\text { Intake } \\
\text { Airflow }\end{array}$ & $\begin{array}{c}\text { Stage } \\
\text { Loader }\end{array}$ & $\begin{array}{l}\text { Shields } \\
\text { Advance }\end{array}$ & $\begin{array}{l}\text { Shearer } \\
\text { Cutting }\end{array}$ \\
\hline C & 3.4 & 35.4 & 28.3 & $6.2 \%$ & $14.9 \%$ & $19.4 \%$ & $59.5 \%$ \\
\hline $\mathbf{E}$ & 3.1 & 23.1 & 21.2 & & & & \\
\hline D & 2.7 & 21.7 & 11.3 & $7.6 \%$ & $24.9 \%$ & $30.1 \%$ & $37.4 \%$ \\
\hline G & 2.7 & 30.5 & 20.3 & $13.2 \%$ & $14.9 \%$ & $35.6 \%$ & $36.3 \%$ \\
\hline $\mathbf{K}$ & 2.7 & 26.6 & 10.9 & $10.9 \%$ & $7.5 \%$ & $21.8 \%$ & $59.8 \%$ \\
\hline $\mathbf{J}$ & 2.4 & 31.5 & 7.6 & $5.5 \%$ & $4.6 \%$ & $7.0 \%$ & $82.9 \%$ \\
\hline $\bar{F}$ & 2.1 & $\begin{array}{l}11.3 \\
\end{array}$ & 30.2 & $8.2 \%$ & $15.2 \%$ & $16.9 \%$ & $59.7 \%$ \\
\hline $\mathbf{L}$ & 2.1 & 18.9 & 23.3 & $16.6 \%$ & $9.1 \%$ & $30.0 \%$ & $44.3 \%$ \\
\hline A & 2.0 & 11.9 & 50.0 & $17.4 \%$ & $20.8 \%$ & $27.1 \%$ & $34.7 \%$ \\
\hline B & 1.8 & 12.5 & 10.9 & $6.5 \%$ & $17.6 \%$ & $31.1 \%$ & $44.8 \%$ \\
\hline H & 1.8 & 21.0 & 17.5 & $12.3 \%$ & $32 \%$ & $25.7 \%$ & $30.0 \%$ \\
\hline I & 1.7 & 24.2 & 11.3 & $2.2 \%$ & $11.1 \%$ & $21.2 \%$ & $65.5 \%$ \\
\hline$M$ & 1.7 & 14.3 & 7.1 & $0.4 \%$ & $4.9 \%$ & $10.1 \%$ & $84.6 \%$ \\
\hline
\end{tabular}

The mines were listed according to their cutting heights and were classified into two categories: thin seam $(\leq 2.1 \mathrm{~m})$ and medium thickness seam $(>2.1 \mathrm{~m})$. Seven mines were classified as thin seam and six mines as medium seam. By analysing the information from Table 4, it is evidenced that thin and medium seams have different contributions from major dust sources within the longwall section. Table 5 shows average dust contribution of major dust sources on longwall faces.

Table 5 Average contribution of major dust sources on longwall faces based on cutting height

\begin{tabular}{|c|c|c|c|c|c|c|c|}
\hline \multirow[t]{2}{*}{ Mine } & \multirow{2}{*}{$\begin{array}{c}\text { Cutting } \\
\text { Height } \\
\text { (m) }\end{array}$} & \multirow{2}{*}{$\begin{array}{c}\text { Cutting } \\
\text { Rate } \\
\text { (t/min) }\end{array}$} & \multirow{2}{*}{$\begin{array}{c}\text { Face Air } \\
\text { Quantity } \\
\left(\mathrm{m}^{3} / \mathrm{s}\right)\end{array}$} & \multicolumn{4}{|c|}{ Contributions from Major Dust Sources } \\
\hline & & & & $\begin{array}{l}\text { Intake } \\
\text { Airflow }\end{array}$ & $\begin{array}{c}\text { Stage } \\
\text { Loader }\end{array}$ & $\begin{array}{c}\text { Shields } \\
\text { Advance }\end{array}$ & $\begin{array}{l}\text { Shearer } \\
\text { Cutting }\end{array}$ \\
\hline $\begin{array}{l}\text { Medium } \\
\text { Seam }\end{array}$ & $\begin{array}{c}2.9 \\
(2.4-3.4)\end{array}$ & $\begin{array}{c}27.5 \\
(21.7-35.4)\end{array}$ & $\begin{array}{c}18.4 \\
(7.6-28.3) \\
\end{array}$ & $\begin{array}{c}9.8 \% \\
(6 \%-13 \%) \\
\end{array}$ & $\begin{array}{c}13.7 \% \\
(5 \%-25 \%) \\
\end{array}$ & $\begin{array}{c}24.4 \% \\
(7 \%-36 \%) \\
\end{array}$ & $\begin{array}{c}52.1 \% \\
(36 \%-83 \%) \\
\end{array}$ \\
\hline $\begin{array}{l}\text { Thin } \\
\text { Seam }\end{array}$ & $\begin{array}{c}1.9 \\
(1.7-2.1)\end{array}$ & $\begin{array}{c}16.3 \\
(11.9-24.2)\end{array}$ & $\begin{array}{c}21.5 \\
(7.1-50.0)\end{array}$ & $\begin{array}{c}8.3 \% \\
(0 \%-17 \%)\end{array}$ & $\begin{array}{c}15.6 \% \\
(5 \%-21 \%)\end{array}$ & $\begin{array}{c}22.0 \% \\
(10 \%-31 \%)\end{array}$ & $\begin{array}{c}54.2 \% \\
(30 \%-85 \%)\end{array}$ \\
\hline
\end{tabular}


With an average cutting height of $2.9 \mathrm{~m}$ and a cutting rate averaged at 27.5 tons per minute, the Medium seam mines have more dust sourced from intake air, shield advance movement when compared with the Thin seam mines with have a cutting height averaged at $1.9 \mathrm{~m}$ and an average cutting rate of 16.3 tons per minute.

On average, intake air accounted for $9.8 \%$ of the dust make for the Medium seam mines and $8.3 \%$ for the Thin seam mines. One explanation for this could be that Medium seam mines might have higher volumes of air supplied to the face with higher airflow velocities in the intake airways. However, this was not the case as average airflow quantities supplied to both categories were compared. Medium seam mines actually had less air quantity on average at $18.4 \mathrm{~m}^{3} / \mathrm{s}$ at average air velocity of $1.8 \mathrm{~m} / \mathrm{s}$ supplied to the faces compared with $21.5 \mathrm{~m}^{3} / \mathrm{s}$ at $3.3 \mathrm{~m} / \mathrm{s}$ supplied to faces for the Thin seam mines. The other reason could be to that normally the Medium seam mines are generating more dust minewide and the chance of intake air to be contaminated with dust is therefore higher.

Shield advance movement also accounted for more (24.4\% compared with $22 \%$ ) of the total dust make for Medium seam mines than the Thin seam mines. This supports earlier research, which indicated that greater levels of respirable dust are generated during shield advance if coal is left in roof, which is commonly found at the thicker seam mines. Both stage loader and shearer cutting accounted for slightly less percentages in the total dust make at the longwall face with Medium seam mines than with Thin seam mines. However, the shearer is still the most significant source of respirable dust generation on the faces regardless of the seam height.

Gravimetric dust samplings including stationary and mobile measurements were collected and summarised during PRC's investigation. An indirect calculation was made to try to work out the average dust concentration contributed by each source at longwall section for all mines considered. This was done by re-examining some of the stationary and mobile gravimetric dust sampling results presented by Colinet et al (1996). The average dust make in $\mathrm{mg} / \mathrm{m}^{3}$ at each source within the longwall section can be calculated from knowing the percentage related to the total dust make and the intake air dust concentration measured as shown in Table 6. For example, dust generated from the stage loader is calculated as

Dust generated at stage loader $=$ (Average intake air dust level $/$ Average intake air $\%$ of total dust make) $\times$ Average stage loader $\%$ of total dust make

$=\left(0.53 \mathrm{mg} / \mathrm{m}^{3} / 9.8 \%\right) \times 13.7 \%$

$=0.74 \mathrm{mg} / \mathrm{m}^{3}$

Table 6 Average dust levels of major dust sources on longwall faces

\begin{tabular}{|l|c|c||c|c|c|c|c|}
\hline & $\begin{array}{c}\text { Cutting } \\
\text { Height } \\
(\mathrm{m})\end{array}$ & $\begin{array}{c}\text { Cutting } \\
\text { Rate } \\
(\mathrm{t} / \mathrm{min})\end{array}$ & $\begin{array}{c}\text { Intake* } \\
\text { Airflow } \\
\left(\mathrm{mg} / \mathrm{m}^{3}\right)\end{array}$ & $\begin{array}{c}\text { Stage } \\
\text { Loader } \\
\left(\mathrm{mg} / \mathrm{m}^{3}\right)\end{array}$ & $\begin{array}{c}\text { Shields } \\
\text { Advance } \\
\left(\mathrm{mg} / \mathrm{m}^{3}\right)\end{array}$ & $\begin{array}{c}\text { Shearer } \\
\text { Cutting } \\
\left(\mathrm{mg} / \mathrm{m}^{3}\right)\end{array}$ & $\begin{array}{c}\text { Total } \\
\left(\mathrm{mg} / \mathrm{m}^{3}\right)\end{array}$ \\
\hline Medium & 2.9 & 27.5 & 0.53 & 0.74 & 1.32 & 2.82 & 5.41 \\
Seam & $(2.4-3.4)$ & $(21.7-35.4)$ & $(9.8 \%)$ & $(13.7 \%)$ & $(24.4 \%)$ & $(52.1 \%)$ & $(100 \%)$ \\
\hline Thin & 1.9 & 16.3 & 0.27 & 0.51 & 0.71 & 1.76 & 3.25 \\
Seam & $(1.7-2.1)$ & $(11.9-24.2)$ & $(8.3 \%)$ & $(15.61 \%)$ & $(22.0 \%)$ & $(54.2 \%)$ & $(100 \%)$ \\
\hline
\end{tabular}

* average of the intake air dust sampling results obtained by Colinet et al (1996).

It is apparent that the Medium seam mines have generated much more respirable dust than the Thin seam mines. Total respirable dust generated within the longwall section is averaged at $5.41 \mathrm{mg} / \mathrm{m}^{3}$ for the Medium seam mines and $3.25 \mathrm{mg} / \mathrm{m}^{3}$ for the Thin seam mines. Figure 1 summaries average gravimetric dust concentration from longwall section for both Medium and Thin seam mines. There is no doubt that thicker seam mines with thicker cutting heights will have higher production rates which means more respirable dust will be generated during mining from intake air, stage loader/crusher, shield advance and shearer as illustrated. 


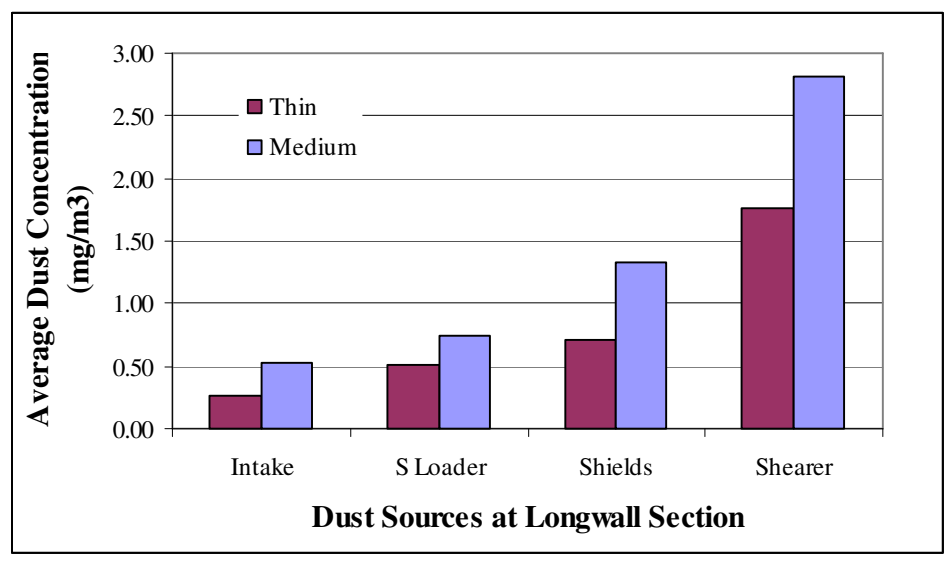

Figure 1 Average dust concentrations of major dust sources on longwall faces

\section{Australian Longwall Dust Situation}

As mentioned previously, overseas experiences can't be translated directly to Australian situations. This is particularly true when comparing the operation conditions of the US longwall and the Australian longwall. For example, in Australia, thick seam longwall mines surveyed during this study have an average cutting height of $4.3 \mathrm{~m}$ with a range varying from 3.8 to $5.0 \mathrm{~m}$. The thickest seam mine in US examined previously is $3.4 \mathrm{~m}$. Therefore, it is necessary to examine the Australian longwall mines to evaluate the effect of thicker seam cutting height on the dust make at longwall faces.

In order to gauge the effect of thick seam mining on the respirable dust makes for Australian longwall, a selection of Joint Coal Board (JCB) respirable dust database results were examined and analysed. The JCB dust database results contain all respirable dust sampling results dated back to 1985 conducted by JCB according to the statutory requirements in NSW (Cram, 1998). There are only three longwall mines in NSW that can be regarded as thick seam mines. Therefore, six longwall mines were selected from JCB dust database with all the three thick seam longwall operations with panel cutting height of more than $3.8 \mathrm{~m}$ classified as Thick seam mines and the other three with panel cutting height of less than $3.8 \mathrm{~m}$ as Normal seam mines. The Normal seam mines were selected based on the similarity of the operational conditions to those of the Thick seam mines.

The JCB samplings were conducted for various mine personnel working at longwall faces such as cableman, electrician, Maingate man/operator, chockman, deputy, fitter, shearer operator and support operator etc. Of these personnel, chockman, deputy and shearer operators are the most important personnel from a dust point of view as they are working most of the shift at longwall faces and have been subjected to dust exposure during the working shift. They are also sampled more frequent than any other personnel at the face.

From an analysis of Joint Coal Board (JCB) respirable dust readings from a number of both Thick seam (greater that $3.6 \mathrm{~m})$ and medium seam $(2.0$ to $3.6 \mathrm{~m})$ mines there appears to be evidence that chockmen in high production thick seam panels are exposed to higher dust exposures than shearer operators as shown in Figure 2.

From Figure 2 it can be seen that over the period under study dust levels in Medium seam mines have been, in general, decreasing. This can be explained from general industry awareness and use of improved technology across the industry. However dust levels on Thick seam mines have remained relatively consistent, progressively increasing higher production rates contributing more dust were counterbalanced by general industry awareness and use of improved technology.

In 1995 dust levels on Medium seam mines were recorded at lower levels than Thick seam mines. This trend has broadly continued from this point. From 1995 it is clearly shown that in the Thick seam mines, chockman have been exposed to higher dust levels than their counterparts in the Medium seam mines. However shearer operators have been exposed to similar dust levels in the Medium 

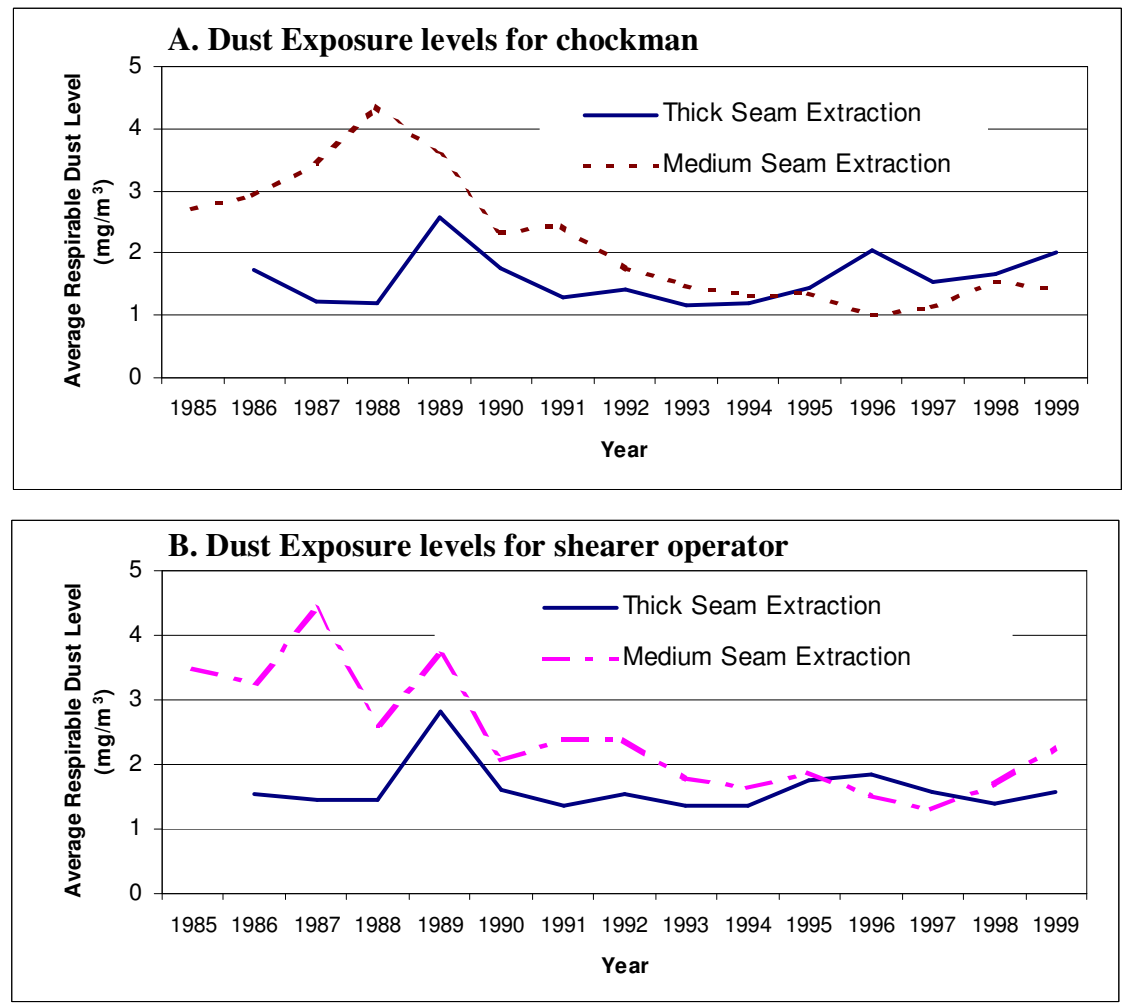

Figure 2 Comparison of yearly dust exposure levels for chockman and shearer operator

seam mines to the Thick seam mine personnel. In some years Thick seam exceeded and in other years the opposite trend was exhibited. In the most recent years since 1995 the trend is for Thick seam chockmen to be exposed to greater dust (average $1.74 \mathrm{mg} / \mathrm{m}^{3}$ compared with $1.63 \mathrm{mg} / \mathrm{m}^{3}$ ) than their shearer colleagues. This same trend is not seen with Medium seam chockmen and Shearer operators. This is in agreement with the previous US finding that the chockman has the higher dust exposure levels for their greater thickness mines. From these analyses it is recommended that more controls be required and employed for chockman to reduce their dust exposure levels. There is an Australian industry perception that the dust exposure levels for chockman and shearer operator have been following increasing trends for the last few years, particularly in mines with dramatically increased levels of production. In order to gain a better understanding of the relation between production and dust exposure levels in longwall sections, average yearly shift productions in the 1990s verses both chockman and shearer operator dust exposure levels for the Thick seam mines are shown in Figure 3.

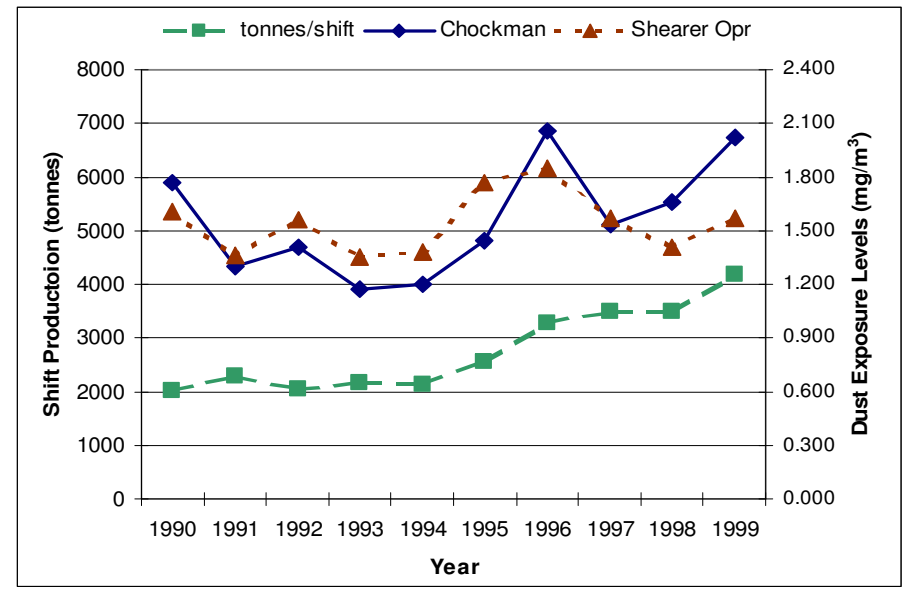

Figure 3 Average shift production verses dust exposure levels for Thick seam mines 
Figure 3 clearly shows that in the 1990s the Thick seam mines examined have doubled their average shift production. Shearer operator dust exposure levels have varied over the years but are on an upward trend. Chockman dust exposure levels were definitely on an upward trend with the increased production particularly in the most recent years.

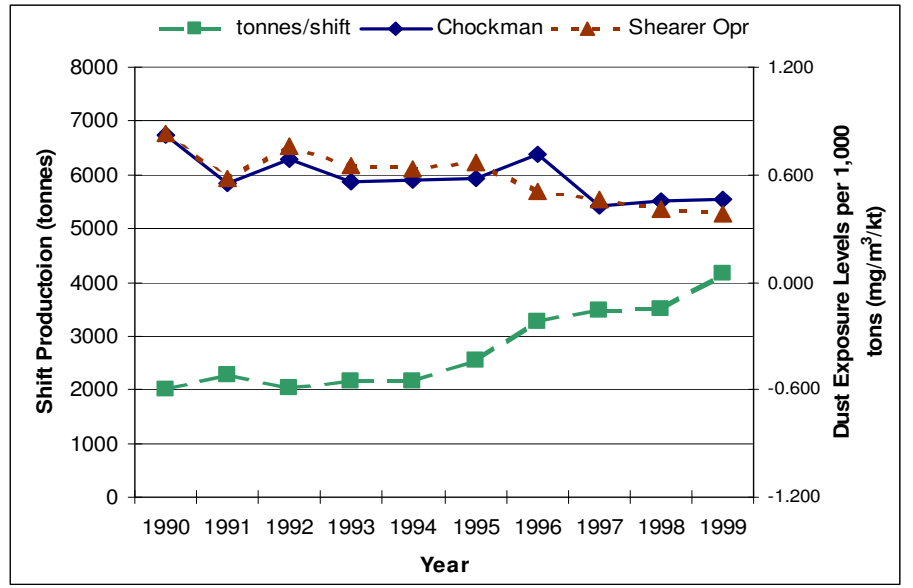

Figure 4 Average shift production verses dust exposure levels per1,000 tonnes coal mined

Figure 4 examines these dust levels on a basis weighted to production. It illustrates average yearly shift productions verses both chockman and shearer operator dust exposure levels per 1,000 tonnes of coal mined. It can be seen that both chockman and shearer operator dust exposure levels per 1,000 tonnes of coal mined were on downward trends in the last decade. This may due to the increased awareness of potential dust problems associated with higher production rates. Mines have introduced dust control strategies either implementing new dust controls or improving existing controls to reduce dust exposures of their miners.

However, based on the findings of the analysis of the JCB dust database results, there is no doubt that Thick seam longwall mines are producing more tonnage. This production results in more respirable dust and better control technologies have at best been level pegging in keeping pace. Chock advance in Thick seam longwalls is generating a relatively greater level of respirable dust than in Medium seam longwall panels. This supports the findings from analysis of US longwall operations.

There may be a number of reasons for these high chockman dust readings. Friable coal is more likely left against roof. High silica dust when working against stone roof. Large chocks can collect a lot of dust which waterfalls into the air stream during lowering and advancement, Canopy sprays with different systems have been tried, approaches include:

- Spraying when chock lowering for advance

- Periodic pulsing sprays make the top of chocks wet at all time

- Frequent washing of supports with hose by hand

Operators often turn off the sprays as dust is less an issue than annoyance from getting wet from falling water. A greater understanding of the following issues is needed.

- Automatic systems for single or batch chock advancement. These have major scope for improving position of chockmen out of the dust.

- Shearer initiated chock advancement; there appears to be a lack of relevant literature on advantages from dust point of view to chockmen?

- Placement of chockmen during "snaking".

- Rotation of chockmen during the shift.

Australian thick seam longwall mining are making effort and giving priority to reducing the respirable dust levels sourced from chock advance operations. 


\section{CONCLUSIONS AND RECOMMEDATIONS}

The results of a detailed questionnaire survey on respirable dust in thick seam coal mines that was undertaken recently in order to achieve a better understanding of respirable dust issues faced by the Australian thick seam longwall operators have been analysed and discussed. High production associated with thick seam longwall, which means more dust generation and increased face air quantity requirements, is the major dust challenge difference between thin seam and thick seam longwall mining.

Shearer and chock advance are regarded as the major sources of dust on the longwall face. Longwall face air quantity is generally targeted between 35 and $70 \mathrm{~m}^{3} / \mathrm{s}$ and averaged around $50 \mathrm{~m}^{3} / \mathrm{s}$. Most of the mines indicated that the targeted amount of air was normally achieved. A divided view on whether more air on the face would assist dust reduction was observed. Three mines believed that more air at face would not assist dust reduction but increase dust pick up and disturb spray operation. Most of mines agreed that there is a maximum face air velocity beyond which they thought airborne dust levels would be exacerbated.

In order to identify the importance of seam thickness on generation of respirable dust on longwall section, US information collected by PRC in the mid 1990s was re-analysed based on the seam thickness during this study. Data from thirteen mines was analysed according to their cutting heights and was classified into two categories: six in thin seam $(\leq 2.1 \mathrm{~m})$ and seven in medium thickness seam $(>2.1 \mathrm{~m})$. From the analysis, it is evidenced that thin and medium seams have different contributions from major dust sources within the longwall section.

With an average cutting height of $2.9 \mathrm{~m}$ and a cutting rate averaged at 27.5 tons per minute, the Medium seam mines have more dust sourced from intake air and chock advance movement when compared with the Thin seam mines with have a cutting height averaged at $1.9 \mathrm{~m}$ and an average cutting rate of 16.3 tons per minute. This supports earlier research, which indicated that greater levels of respirable dust are generated during chock advance if coal is left at roof, which is commonly found at the thicker seam mines. However, the shearer is still the most significant source of respirable dust generation on the faces regardless of the seam height.

An indirect calculation was made to try to work out the average dust concentration contributed by each source at longwall section for all mines considered. This was done by re-examining some of the stationary and mobile gravimetric dust sampling results presented by Colinet et al. The average dust make in $\mathrm{mg} / \mathrm{m}^{3}$ at each source within the longwall section can be calculated from knowing the percentage related to the total dust make and the intake air dust concentration measured. It was found obviously that the Medium seam mines have generated much more respirable dust that the thin seam mines. Total dust generated within the longwall section is averaged at $5.41 \mathrm{mg} / \mathrm{m}^{3}$ for the Medium seam mines and $3.25 \mathrm{mg} / \mathrm{m}^{3}$ for the thin seam mines.

As overseas experiences can't be translated directly to Australian situations, to determine the effect of thick seam mining on the respirable dust makes for Australian longwall, a selection of JCB respirable dust database results were examined and analysed. Six longwall mines were selected with three thick seam operations with panel cutting height of more than $3.8 \mathrm{~m}$ classified as Thick seam mines and the other three as Normal seam mines which were chosen based on the similarity of the operational conditions to those of the Thick seam mines.

Based on the findings of the analysis of the JCB dust database results, there is no doubt that Australian thick seam longwall mines were producing more tonnage in recent years. This production results in more respirable dust and improved control technologies have at best been level pegging in keeping pace. Chock advance movement in thick seam longwall is generating a relatively greater level of respirable dust than in normal or thinner seam longwall panels. This supports the findings from analysis of US longwall operations. Australian thick seam longwall mining should give some priority to reducing the respirable dust levels sourced from chock advance operations.

Review of overseas technology developments must take into account the nature of individual national industries. Modern longwall methods are only in use in a small number of countries. Western European coal operators are backing out of underground extraction. South Africans has found longwall technology unsuitable for most of their seams. The US have about 65 modern longwall faces 
but almost all are extracting at thin or medium seam heights. A few Western state mines are working at higher seam thicknesses but not in excess of 3.5 to $4.0 \mathrm{~m}$ The Canadian underground coal industry has virtually closed.

Australia has about seven modern high production longwalls cutting at 3.8 to $5.0 \mathrm{~m}$ seam thickness. More thick seam extraction mines are planned. With high, and often record breaking, production rates dust is potentially a major issue. As such the situation faced is unique and different to conditions faced in the rest of the world. The approaches and previous innovation from research and experiences in other countries (particularly the US, Western Europe and South Africa) are not necessarily directly transferable for solving Australian issues.

\section{ACKNOWLEDGEMENT}

The support of the Australian Coal Industry Research Program in funding this study is acknowledged. The study would not have been possible without the cooperation of the mine sites that took part in the surveys and sponsored and sent representatives to participate in the Workshops. They are thanked for this support. Professor Raj V Ramani of the Pennsylvania State University was sponsored to visit Australia. His knowledge in the area of respirable dust and interest to support the project were invaluable to its success. Mr Ken Cram of the Joint Coal Board and Dr Jan Oberholzer of SIMTARS gave considerable time, advice and cooperation to the project and thanks is extended for this cooperation. Mr Tim Mayes of the University of Queensland gave extensive support and advice and his contributions are acknowledged.

\section{REFERENCES}

Colinet, J.F., Spencer, E.R. and Jankowski, R.A 1996, "Status of Dust Control Technology on US Longwalls", Proceeding $6^{\text {th }}$ International Mine Ventilation Congress, Pittsburgh, pp. 345-351.

Cram, K., 1998, "Longwall Mines Workplace Environmental Issues," Proceeding 1998 Australian Longwall Mining Summit, IBC, Sydney, $17 \mathrm{pp}$.

Gillies, A.D.S. 2001 Dust Measurement and Control in Thick Seam Mining, Report to ACARP Project No. C9002, Australian Coal Research Ltd, Brisbane, 109 pp. 